\title{
Rabaska
}

Revue d'ethnologie de l'Amérique française

\section{LÉGÈRE, LUC, sous la direction de RONALD LABELLE. Répertoire des collections de contes folkloriques. Moncton, Université de Moncton, Centre d'études acadiennes, 2002, 110 p. ISBN 0-91924-69-7}

\section{Faith Williams}

Volume 3, 2005

URI : https://id.erudit.org/iderudit/201731ar

DOI : https://doi.org/10.7202/201731ar

Aller au sommaire du numéro

Éditeur(s)

Société québécoise d'ethnologie

ISSN

1703-7433 (imprimé)

1916-7350 (numérique)

Découvrir la revue

Citer ce compte rendu

Williams, F. (2005). Compte rendu de [LÉGÈRE, LUC, sous la direction de RONALD LABELLE. Répertoire des collections de contes folkloriques. Moncton, Université de Moncton, Centre d'études acadiennes, 2002, 110 p. ISBN 0-91924-69-7]. Rabaska, 3, 160-160. https://doi.org/10.7202/201731ar d'utilisation que vous pouvez consulter en ligne. 
LÉGÈRE, LUC, sous la direction de RONALD LABELLE. Répertoire des collections de contes folkloriques. Moncton, Université de Moncton, Centre d'études acadiennes, 2002, 110 p. ISBN 0-91924-69-7.

Les spécialistes de la littérature orale savent combien le conte populaire tient une place importante dans le répertoire acadien. Cet ouvrage, préparé par Luc Légère, vise justement à guider les chercheurs dans cet ensemble volumineux. Il recense les 135 collections conservées dans les archives du Centre d'études acadiennes de l'Université de Moncton, totalisant 1500 récits parmi les 4000 contes acadiens connus - d'autres centres, comme les Archives de folklore de l'Université Laval, en conservent aussi un grand nombre. Cette abondante moisson a été recueillie dans plusieurs provinces de l'est du Canada (Nouveau-Brunswick, Nouvelle-Écosse, Île-du-Prince-Édouard, Québec) et en Louisiane, aux États-Unis, par d'éminents experts comme Luc Lacourcière, ses étudiantes Catherine Jolicoeur et Antonine Maillet, puis par de jeunes chercheurs comme Georges Arsenault, et plus tard, Robert Richard. Des 317 informateurs, comprenant légèrement plus d'hommes (173) que de femmes (141), qui ont fourni ces narrations, six ont livré la moitié des contes de ce répertoire ; parmi eux, se détachent quelques noms comme Séraphie Martin et Exilda Hébert de Richibouctou (N.-B.) et Léon Rossignol de Saint-Andréde-Madawaska (N.-B.), qui ont livré chacun une centaine de contes.

Le Répertoire des collections de contes folkloriques présente des données dans l'ordre alphabétique sous le nom des informateurs. On peut y lire un aperçu de la personnalité de chacun avec la durée moyenne des enregistrements. Puis le catalogue donne le lieu de l'enquête, le numéro de la collection, les dates et la qualité sonore de l'enregistrement, le nombre des contes et indique s'il y a des transcriptions. Pour chaque pièce, l'ouvrage ajoute d'autres précisions : le numéro de l'enregistrement et de la bobine, le conte-type, le nombre de pages de la transcription et le titre donné. À la fin du catalogue, se trouve un index de tous les collecteurs. Voilà un outil de recherche très utile pour ceux qui s'intéressent aux contes populaires acadiens.

Faith Williams Université Sainte-Anne, Pointe-de-l'Église 